\title{
Development and validation of a questionnaire on knowledge and practices of disinfection and sterilization among healthcare workers
}

\author{
(1) Nazmi Liana Azmi, (1) Nur Maisarah Abu Bakar, (1) Norhafiza Ismail Abdul Rashid, (1) Nurul Musfirah Mafauzy, \\ (1) Ahmad Syarafi Mat Hussin Mohamed, (1) Nurul Ainina Mohamad, (1) Siti Hamisah Said, \\ (1) Nur Izzati Ahmad Zawawi, (1) Nik Siti Fairuz Mohamed
}

Raja Perempuan Zainab II Hospital, Ministry of Health Malaysia, Department of Pharmacy, Kelantan, Malaysia

Date submitted:

11.12.2020

Date accepted:

05.02.2021

Online publication date:

15.12.2021

\section{Corresponding Author:}

Nazmi Liana Azmi, Raja Perempuan Zainab II Hospital, Ministry of Health Malaysia, Department of Pharmacy, Kelantan, Malaysia

nazmiliana@moh.gov.my

ORCID:

orcid.org/0000-0002-1416-0609

Keywords: Disinfection, sterilization, knowledge, practices, validation, questionnaire

\begin{abstract}
Aims: To develop and validate a questionnaire to measure knowledge and practices of disinfection and sterilization among healthcare workers.

Methods: A self-administered questionnaire in Bahasa Melayu, comprising 2 sections of knowledge (15 items) and practices (15 items), was developed based on available literature and expert opinions. Content validity was assessed by 9 experts while face validity was tested on 12 subjects. Psychometric properties were evaluated on 67 respondents in the pilot study, using 2 parameter logistic item response theory (2PL-IRT), exploratory factor analysis (EFA) and Cronbach's alpha. Data were analyzed with $\mathrm{R}$ version 3.5.1.
\end{abstract}

Results: The content validity index for knowledge and practices were 0.96 and 0.92 (after omitting 2 items), respectively, denoting good relevancy of the items. Assessment of face validity index showed the values of 0.86 for knowledge and 0.83 for practices (after dropping 1 item), indicating that the questionnaire was well-understood by respondents. In the pilot study, 2PL-IRT and EFA revealed that the questionnaire had good psychometric properties after the removal of 2 poor quality items from each section. As for internal consistency, Cronbach's alpha coefficients were determined to be acceptable; 0.72 [95\% confidence interval (Cl): 0.623 , 0.818 ] for knowledge and $0.803(95 \% \mathrm{Cl}: 0.733,0.803)$ for practices. The validated questionnaire consisted of a total of 23 items; knowledge ( 13 items) and practices (10 items).

Conclusions: A self-administered questionnaire on knowledge and practices of disinfection and sterilization among healthcare workers was developed and validated. Future recommendation is for confirmatory analysis to be carried out to verify and maximize the psychometric credentials of the questionnaire.

\section{Introduction}

Despite progress and advancement in public health and hospital care, infections continue to develop in hospitalized patients and are arising tremendously every year (1). Nosocomial or hospital acquired infections are infections that are not present during the time of admission. They can manifest 48 hours after admission to the hospital and even after the discharge of the patients (2). They do not only burden the hospital workers but also affect the cost resources as they effectuate prolonged stay, persistent disability, increased antimicrobial resistance and elevated the mortality rate worldwide (3).
According to World Health Organization estimation, up to $15 \%$ of all hospitalized patients suffer from these nosocomial infections (4). In Malaysia, the prevalence was $13.9 \%$ with the most common infections including clinical sepsis and pneumonia (5). This is because during hospitalization, the patient is exposed to multiple pathogens from different sources such as the environment, healthcare providers and other infected patients (2). Transmission of these infections should be kept at bay with appropriate infection control measures (6).

Among the first actions is by maintaining the hospital environment and equipment clean with proper disinfection and 
sterilization practices $(7,8)$. The Guideline for Disinfection and Sterilization in Healthcare Facilities describes disinfection as a process that eliminates many or all pathogenic microorganisms except for bacterial spores. On the other hand, sterilization does the latter and is defined as a process that destroys all forms of microbial life through physical or chemical means (9).

Available publications addressed that there was inadequate knowledge or unsatisfactory practices or both regarding disinfection and sterilization which was despairing considering its impact on patients' safety (10-13). To the best of the authors' knowledge, all of the questionnaires used were of foreign languages and there was no detailed information on their development, which makes it difficult to be applied in the population of Malaysia. The sole local work by Keah et al. (14) was a good reference to start with but the tool could be outdated with all the recent policies and guidelines. Thus, this study aimed to develop and validate a questionnaire on knowledge and practices of disinfection and sterilization among healthcare workers in Bahasa Melayu or the Malay language.

\section{Methods}

\section{Phase 1: Questionnaire Development}

A thorough and comprehensive review and searching of the literature was conducted to ascertain existing, as well as to identify relevant items and scales in existing questionnaires on disinfection and sterilization. The first draft of a self-administered questionnaire in Bahasa Melayu was then developed by the research team along with panel of experts based on the compilation of guidelines and scientific articles. The first phase of the study was carried out from July to December 2018.

\section{Content Validation Using Content Validity Index}

Content validation was used to assess whether the content of the questionnaire was appropriate and relevant to study purpose by the same panel of experts. Each expert independently rated the relevancy of the items using a 4-point Likert scale (1=not relevant, 2=need some amendment, 3=relevant, 4=very relevant). Content validity index (CVI) for each item (I-CVI) was computed with Microsoft Excel (15) as the number of experts giving a rating of either 3 or 4 , divided by the number of experts with the cut-off point of 0.78 (16). The questionnaire was then modified based on the expert reviews to produce the second draft.

\section{Face Validation Using Face Validity Index}

Face validation on the second draft of the questionnaire was conducted on 12 respondents from the target population to evaluate the clarity and comprehensibility of the wording used in the developed questionnaire. The respondents assessed each item using a 4-point Likert scale ranging from 1 (item not clear and not understandable) to 4 (clear and understandable) (17). Face validity index (FVI) for each item (I-FVI) was calculated with Microsoft Excel (15) as the number of respondents who rated 3 or 4 , divided by the number of respondents with the threshold of 0.70 (18). The revised version of the questionnaire was formulated based on the findings to be used on the later stage.

\section{Phase 2: Validation Study}

To further explore and evaluate the psychometric properties of the questionnaire, the revised version was self-administered to respondents which were healthcare workers who handled disinfectant directly in Raja Perempuan Zainab II Hospital (HRPZ II), Kelantan. Those who were not available during the data collection period from January to June 2019 due to sabbatical or maternity leave were excluded. They were first briefed about the study and informed consent was then obtained from the respondents who agreed to be involved in the study. For the pilot study, a minimum sample size of 57 was calculated using a web-based sample size calculator for reliability studies (19). The required sample size for 2-parameter logistic item response theory (2PL-IRT) and exploratory factor analysis (EFA) followed the same sample size as internal consistency and it was inflated to 66 to account for $15 \%$ drop-out rate. The data analysis was performed in $\mathrm{R}$ version 3.5.1 (20) using the $\mathrm{R}$ studio environment (21).

\section{PL-IRT Analysis}

As the knowledge section consisted of categorical responses, it was analyzed by 2PL-IRT, using the Itm package version 1.1-1 (22). Difficulty in the range from -3 to +3 and discrimination of $>0.65$ were considered acceptable. Item fit was tested using the chi-square goodness-of-fit per item and unidimensionality was determined by modified parallel analysis (23).

\section{Exploratory Factor Analysis}

The practice section had ordinal responses and therefore, it was analyzed by EFA using the psych package version 2.0.9 (24). The principal axis factoring extraction method with oblimin rotation was applied in EFA (25). The items in each section were treated as continuous responses to allow the evaluation of the dimensionality of the items (25). To determine the number of extracted factors, eigenvalues $>1.0$, parallel analysis and scree plot examination were carried out (26). Factor loadings of $\geq 0.3$ were considered acceptable (25). A Cronbach's alpha coefficient of $>0.7$ was considered as acceptable internal consistency reliability (27).

\section{Ethical Approval}

Permission to conduct the study at the site was obtained from the Director of HRPZ II. All subjects were remained as anonymous to ensure their privacy and confidentiality. All study 
procedures were carried out in accordance with the Declaration of Helsinki and Good Clinical Practice.

\section{Results}

\section{Phase 1: Questionnaire Development}

A self-administered questionnaire in Bahasa Melayu comprising 2 sections of knowledge ( 15 items) and practices (15 items) was developed based on available literature and expert opinions. Items for knowledge were multiple-choice questions with "True", "False" and "Uncertain" answer options, while items for practices had a response of 5-point Likert scale with $1=$ =always, $2=$ often, $3=$ sometimes, $4=$ rarely and $5=$ never and 5 of them were negative statements.

\section{Content Validation Using CVI}

The relevancy of the items was rated using CVI by 9 panel experts who consisted of 2 infectious disease specialists, 2 medical officers, 3 clinical pharmacists and 1 pharmacist in charge of galenical pharmacy. In the knowledge section, all of the experts evaluated 10 items as relevant, thus providing $\mathrm{I}-\mathrm{CVI}=1.00$. The remaining 5 items had calculated $\mathrm{I}-\mathrm{CVI}=0.89$. With $C V I$ average $=0.96$, all items were retained.

In the practices section, only 5 items were rated as relevant by all experts; I-CVI=1.00. Another 7 items had calculated $\mathrm{I}-\mathrm{CV} \mathrm{I}=0.89$, while 1 item scored $\mathrm{I}-\mathrm{CVI}=0.78$. The first 2 items of Q1: "I perform endotracheal tube disinfection using alcohol swab" and Q2: "I use sterile chlorhexidine $2 \%$ in alcohol $70 \%$ for multiple patients" were deleted due to $\mathrm{I}-\mathrm{CVI}<0.78$. With 13 items remaining in the practices section, $\mathrm{I}-\mathrm{CVI}$ average improved from 0.89 to 0.92 (Table 1).

\section{Face Validation Using FVI}

The clarity of the items was assessed using FVI in 12 respondents. In the knowledge section, 3 items appeared to be clear and understandable by all target population ( $F V I=1.00)$. Another 4 items had $F V I=0.92$, while the remaining 5 items scored $\mathrm{FVI}=0.75$. With $\mathrm{FVI}$ average of 0.86 , all 15 items were retained.

For the practices section, only 1 item was clear and understandable by all target population $(F V I=1.00)$. Out of 13 questions, 2 items obtained $\mathrm{FVI}=0.92$, while the rest 9 items scored $\mathrm{FVI}=0.75-0.83$. Q10 "I perform nebulizer disinfection during every treatment" had the lowest $\mathrm{FVI}=0.5$ and was omitted from the questionnaire, which increased $\mathrm{FVI}$ average from 0.8 to 0.83 for 12 items (Table 2). Therefore, the revised version of the questionnaire consisted of a total of 27 items, with knowledge (15 items) and practices (12 items).

\section{Phase 2: Validation Study}

Evaluation of the psychometric properties was carried out using 67 respondents in the pilot study. Majority of them were female $(64.2 \%, \mathrm{n}=43)$, with mean [standard deviation (SD)] age of 35.6 (8.43) years. They were mostly Malays (95.5\%, $n=64)$, working as nurses $(34.3 \%, n=23)$ with mean (SD) working experience of 11.3 (8.2) years. More than half of the respondents had never attended any infection control course $(53.7 \%, n=36)$ (Table 3).

\begin{tabular}{|c|c|c|c|c|c|c|c|c|c|c|}
\hline Items & $\begin{array}{l}\bar{t} \\
\frac{t}{0} \\
\frac{0}{x}\end{array}$ & $\begin{array}{l}\text { N } \\
\frac{t}{0} \\
\frac{0}{x} \\
\text { ய }\end{array}$ & $\begin{array}{l}m \\
\frac{t}{\otimes} \\
\frac{0}{x} \\
\text { ü }\end{array}$ & $\begin{array}{l}\forall \\
\frac{t}{d} \\
\frac{0}{x} \\
\text { ய }\end{array}$ & $\begin{array}{l}\text { L } \\
t \\
\frac{t}{d} \\
\frac{0}{x} \\
\text { ú }\end{array}$ & $\begin{array}{l}0 \\
t \\
\text { ț } \\
\frac{0}{x} \\
\text { ú }\end{array}$ & $\begin{array}{l}\hat{t} \\
\frac{t}{0} \\
\stackrel{0}{x} \\
\text { ư }\end{array}$ & $\begin{array}{l}\infty \\
t \\
\frac{t}{0} \\
\frac{0}{x} \\
\text { w }\end{array}$ & $\begin{array}{l}\text { o } \\
\frac{t}{0} \\
\frac{0}{x} \\
\text { ய }\end{array}$ & I-CVI \\
\hline \multicolumn{11}{|c|}{ Knowledge section } \\
\hline Q1 & 4 & 4 & 4 & 4 & 4 & 4 & 4 & 4 & 4 & 1.00 \\
\hline Q2 & 4 & 4 & 4 & 4 & 4 & 4 & 3 & 4 & 4 & 1.00 \\
\hline Q3 & 4 & 4 & 4 & 4 & 4 & 4 & 4 & 4 & 4 & 1.00 \\
\hline Q4 & 3 & 4 & 4 & 4 & 4 & 4 & 4 & 4 & 3 & 1.00 \\
\hline Q5 & 4 & 4 & 4 & 4 & 4 & 4 & 4 & 2 & 4 & 0.89 \\
\hline Q6 & 4 & 4 & 4 & 4 & 4 & 2 & 4 & 4 & 3 & 0.89 \\
\hline Q7 & 4 & 4 & 4 & 4 & 4 & 4 & 4 & 4 & 4 & 1.00 \\
\hline Q8 & 4 & 4 & 4 & 4 & 4 & 4 & 3 & 4 & 2 & 0.89 \\
\hline Q9 & 4 & 4 & 4 & 4 & 4 & 3 & 4 & 4 & 4 & 1.00 \\
\hline Q10 & 4 & 4 & 4 & 4 & 4 & 4 & 4 & 4 & 4 & 1.00 \\
\hline Q11 & 4 & 3 & 4 & 4 & 4 & 4 & 4 & 4 & 2 & 0.89 \\
\hline Q12 & 4 & 4 & 4 & 4 & 4 & 4 & 4 & 4 & 4 & 1.00 \\
\hline Q13 & 4 & 4 & 4 & 4 & 4 & 4 & 3 & 4 & 4 & 1.00 \\
\hline Q14 & 4 & 3 & 4 & 4 & 4 & 4 & 4 & 4 & 2 & 0.89 \\
\hline Q15 & 4 & 4 & 4 & 4 & 4 & 4 & 4 & 4 & 4 & 1.00 \\
\hline CVI av & & & & & & & & & & 0.96 \\
\hline \multicolumn{11}{|c|}{ Practices section } \\
\hline Q1 & 1 & 4 & 4 & 4 & 4 & 2 & 4 & 2 & 4 & 0.67 \\
\hline Q2 & 3 & 4 & 3 & 4 & 4 & 2 & 4 & 1 & 2 & 0.67 \\
\hline Q3 & 3 & 4 & 4 & 4 & 4 & 4 & 4 & 4 & 4 & 1.00 \\
\hline Q4 & 4 & 4 & 4 & 4 & 4 & 4 & 4 & 4 & 4 & 1.00 \\
\hline Q5 & 4 & 4 & 4 & 4 & 4 & 4 & 4 & 4 & 4 & 1.00 \\
\hline Q6 & 1 & 3 & 4 & 4 & 4 & 4 & 4 & 4 & 4 & 0.89 \\
\hline Q7 & 4 & 4 & 4 & 4 & 4 & 3 & 4 & 4 & 2 & 0.89 \\
\hline Q8 & 1 & 4 & 4 & 4 & 4 & 4 & 4 & 4 & 4 & 0.89 \\
\hline Q9 & 1 & 2 & 4 & 4 & 4 & 4 & 4 & 4 & 4 & 0.78 \\
\hline Q10 & 4 & 2 & 4 & 4 & 4 & 4 & 4 & 3 & 4 & 0.89 \\
\hline Q11 & 1 & 4 & 4 & 4 & 4 & 4 & 4 & 4 & 4 & 0.89 \\
\hline Q12 & 1 & 3 & 4 & 4 & 4 & 4 & 4 & 4 & 4 & 0.89 \\
\hline Q13 & 4 & 4 & 4 & 4 & 4 & 4 & 4 & 4 & 4 & 1.00 \\
\hline Q14 & 1 & 4 & 4 & 4 & 4 & 4 & 4 & 4 & 4 & 0.89 \\
\hline Q15 & 4 & 4 & 4 & 4 & 4 & 4 & 4 & 4 & 4 & 1.00 \\
\hline \multicolumn{10}{|c|}{ CVI average } & 0.89 \\
\hline \multicolumn{10}{|c|}{ CVI average after deletion of Q1 and Q2 } & 0.92 \\
\hline I-CVI: & tent & alidity & ndex & 《. & Solits & & & & & \\
\hline
\end{tabular}




\section{PL-IRT Analysis}

As shown by the 2PL-IRT analysis, the psychometric credentials of knowledge section were good. Most of knowledge items were within or close to the acceptable range from -3 to +3 for difficulty and $<0.65$ for discrimination. Item fit statistics showed all $p$ values $>0.05$. On the assessment of fit for twoway margins, all item pairs showed good fit. Modified parallel analysis supported unidimensionality.

\begin{tabular}{|c|c|c|c|c|c|c|c|c|c|c|c|c|c|}
\hline Items & 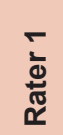 & $\begin{array}{l}\text { N } \\
\stackrel{ \pm}{ \pm} \\
\stackrel{\mathbb{\pi}}{\mathbb{N}}\end{array}$ & 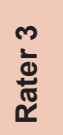 & 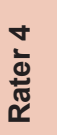 & 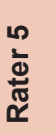 & 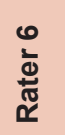 & 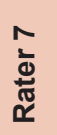 & $\begin{array}{l}\infty \\
\stackrel{ \pm}{ \pm} \\
\stackrel{\pi}{\pi} \\
\mathbb{\Sigma}\end{array}$ & 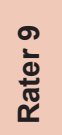 & 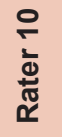 & 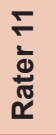 & 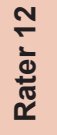 & I-FVI \\
\hline \multicolumn{14}{|c|}{ Knowledge section } \\
\hline Q1 & 4 & 4 & 3 & 2 & 3 & 2 & 3 & 3 & 3 & 4 & 3 & 1 & 0.75 \\
\hline Q2 & 4 & 4 & 4 & 4 & 4 & 3 & 4 & 3 & 3 & 4 & 4 & 1 & 0.92 \\
\hline Q3 & 4 & 4 & 4 & 3 & 4 & 4 & 4 & 1 & 4 & 4 & 4 & 4 & 0.92 \\
\hline Q4 & 4 & 3 & 3 & 4 & 3 & 3 & 1 & 1 & 3 & 3 & 4 & 3 & 0.83 \\
\hline Q5 & 4 & 3 & 4 & 3 & 3 & 4 & 4 & 3 & 4 & 4 & 4 & 4 & 1.00 \\
\hline Q6 & 3 & 2 & 3 & 1 & 3 & 3 & 3 & 4 & 3 & 2 & 3 & 3 & 0.75 \\
\hline Q7 & 4 & 3 & 3 & 3 & 1 & 2 & 3 & 4 & 3 & 2 & 3 & 3 & 0.75 \\
\hline Q8 & 4 & 3 & 3 & 3 & 1 & 3 & 4 & 2 & 2 & 3 & 3 & 3 & 0.75 \\
\hline Q9 & 3 & 4 & 3 & 2 & 3 & 4 & 3 & 4 & 4 & 4 & 2 & 3 & 0.83 \\
\hline Q10 & 4 & 2 & 4 & 2 & 3 & 3 & 3 & 3 & 3 & 3 & 1 & 3 & 0.75 \\
\hline Q11 & 4 & 4 & 4 & 4 & 3 & 3 & 3 & 1 & 3 & 3 & 1 & 3 & 0.83 \\
\hline Q12 & 4 & 4 & 4 & 4 & 4 & 1 & 3 & 3 & 3 & 4 & 3 & 4 & 0.92 \\
\hline Q13 & 4 & 4 & 4 & 4 & 3 & 4 & 4 & 4 & 4 & 4 & 4 & 4 & 1.00 \\
\hline Q14 & 4 & 4 & 4 & 3 & 4 & 3 & 4 & 4 & 3 & 4 & 4 & 4 & 1.00 \\
\hline Q15 & 4 & 4 & 4 & 4 & 2 & 4 & 3 & 4 & 3 & 4 & 4 & 4 & 0.92 \\
\hline FVI av & ge & & & & & & & & & & & & 0.86 \\
\hline \multicolumn{14}{|c|}{ Practices section } \\
\hline Q3 & 4 & 3 & 3 & 4 & 3 & 2 & 3 & 4 & 3 & 2 & 3 & 3 & 0.83 \\
\hline Q4 & 4 & 4 & 4 & 4 & 4 & 2 & 4 & 4 & 4 & 4 & 2 & 4 & 0.83 \\
\hline Q5 & 4 & 4 & 4 & 4 & 3 & 3 & 4 & 3 & 4 & 4 & 2 & 4 & 0.92 \\
\hline Q6 & 4 & 4 & 4 & 3 & 3 & 3 & 3 & 3 & 4 & 3 & 3 & 3 & 1.00 \\
\hline Q7 & 4 & 4 & 4 & 4 & 3 & 4 & 3 & 2 & 4 & 3 & 1 & 3 & 0.83 \\
\hline Q8 & 4 & 4 & 1 & 4 & 4 & 3 & 3 & 4 & 4 & 3 & 3 & 1 & 0.83 \\
\hline Q9 & 4 & 3 & 1 & 4 & 3 & 3 & 2 & 4 & 4 & 3 & 1 & 3 & 0.75 \\
\hline Q10 & 4 & 3 & 1 & 2 & 2 & 3 & 3 & 2 & 3 & 1 & 3 & 1 & 0.5 \\
\hline Q11 & 3 & 4 & 3 & 1 & 1 & 3 & 4 & 3 & 4 & 3 & 3 & 2 & 0.75 \\
\hline Q12 & 4 & 3 & 2 & 2 & 3 & 3 & 2 & 3 & 3 & 4 & 3 & 3 & 0.75 \\
\hline Q13 & 4 & 4 & 3 & 4 & 3 & 2 & 4 & 3 & 4 & 4 & 4 & 1 & 0.83 \\
\hline Q14 & 4 & 3 & 1 & 3 & 3 & 2 & 4 & 3 & 4 & 4 & 4 & 1 & 0.75 \\
\hline Q15 & 4 & 4 & 3 & 4 & 3 & 3 & 4 & 3 & 4 & 3 & 4 & 1 & 0.92 \\
\hline \multicolumn{13}{|c|}{ FVI average } & 0.81 \\
\hline \multicolumn{13}{|c|}{ FVI average after deletion of Q10 } & 0.83 \\
\hline \multicolumn{14}{|c|}{ I-FVI: Item face validity index, Q: Question } \\
\hline
\end{tabular}

Q3 "To avoid cross contamination, reusable medical equipment should be cleaned and sterilized" was dropped as it was too difficult with poor discrimination while Q5 "Disinfection process should be carried out using appropriate chemical disinfectant" was omitted as it was too easy with low discrimination. Q10 "Glutaraldehyde is used to disinfect heat sensitive equipment" was retained for its average difficulty and good fit despite its low discrimination.

After repeated analysis and modifications, Q13 "Example of semi-critical item is surgical instrument" was kept for its average difficulty and good discrimination even though $p$ value was <0.05 (Table 4). Cronbach's alpha coefficients was 0.72 [95\% confidence interval $(\mathrm{Cl}): 0.623,0.818]$, which deemed as acceptable.

\section{EFA}

In the practices section, Kaiser-Meyer-Olkin Measure of sampling adequacy $=0.75$ and Bartlet's test of sphericity $(p<0.001)$ showed the items were correlated and suitable for EFA. Scree plot demonstrated the suitable factor as 1 even though parallel analysis suggested that the possible number of factors was 3 . Further analysis revealed that very simple structure had the highest value of 0.65 while Velicer's minimum average partial had the smallest value of 0.037 at 1 factor.

Table 3. Demographic characteristics of respondents in the pilot study $(n=67)$

\begin{tabular}{ll}
\hline Demographic characteristics & $\mathbf{n}(\%)$ \\
\hline Age (years old) & $35.6(8.4)^{*}$ \\
\hline Gender & \\
\hline Male & $24(35.8)$ \\
\hline Female & $43(64.2)$ \\
\hline Race & \\
\hline Malay & $64(95.5)$ \\
\hline Non-Malay & $3(4.5)$ \\
\hline Occupation & \\
\hline Medical officer & $9(13.4)$ \\
\hline Pharmacist & $15(22.4)$ \\
\hline Nurse & $23(34.3)$ \\
\hline Medical assistant & $20(29.9)$ \\
\hline Working experience (years) & $11.3(8.2)^{*}$ \\
\hline Education level & \\
\hline Diploma & $42(62.7)$ \\
\hline Degree & $23(34.3)$ \\
\hline Master & $2(3.0)$ \\
\hline Attended infection control course & $31(46.3)$ \\
\hline Yes & $36(53.7)$ \\
\hline No & \\
\hline *: Mean (standard deviation) & \\
\hline
\end{tabular}




\begin{tabular}{|c|c|c|c|c|}
\hline Items & Difficulty & Discrimination & $x^{2}(d f=13)$ & $p$ value \\
\hline \multicolumn{5}{|c|}{ Before modification } \\
\hline Q1 & 0.12 & 1.55 & 8.17 & 0.418 \\
\hline Q2 & -1.42 & 8.74 & 0.13 & 0.999 \\
\hline Q3 & -8.23 & 0.38 & 6.75 & 0.564 \\
\hline Q4 & -2.13 & 0.68 & 5.19 & 0.737 \\
\hline Q5 & 3.29 & -1.31 & 4.56 & 0.803 \\
\hline Q6 & -1.42 & 1.29 & 8.49 & 0.387 \\
\hline Q7 & 0.62 & 1.16 & 8.81 & 0.358 \\
\hline Q8 & -0.09 & 1.80 & 8.04 & 0.429 \\
\hline Q9 & 0.84 & 1.74 & 10.20 & 0.252 \\
\hline Q10 & 0.72 & 0.49 & 9.57 & 0.297 \\
\hline Q11 & -0.17 & 1.21 & 10.37 & 0.240 \\
\hline Q12 & 0.67 & 1.05 & 5.59 & 0.693 \\
\hline Q13 & 0.12 & 0.84 & 12.71 & 0.122 \\
\hline Q14 & -1.42 & 1.80 & 12.87 & 0.116 \\
\hline Q15 & -2.39 & 1.31 & 9.00 & 0.340 \\
\hline \multicolumn{5}{|c|}{ After modification } \\
\hline Q1 & 0.12 & 1.64 & 4.82 & 0.777 \\
\hline Q2 & -1.42 & 8.59 & 0.14 & 0.999 \\
\hline Q4 & -2.17 & 0.67 & 6.91 & 0.546 \\
\hline Q6 & -1.45 & 1.25 & 9.70 & 0.287 \\
\hline Q7 & 0.61 & 1.19 & 12.25 & 0.140 \\
\hline Q8 & -0.09 & 1.79 & 7.54 & 0.480 \\
\hline Q9 & 0.88 & 1.62 & 4.41 & 0.818 \\
\hline Q10 & 0.73 & 0.48 & 9.08 & 0.336 \\
\hline Q11 & -0.17 & 1.26 & 8.28 & 0.407 \\
\hline Q12 & 0.66 & 1.08 & 7.37 & 0.497 \\
\hline Q13 & 0.12 & 0.81 & 20.13 & 0.010 \\
\hline Q14 & -1.42 & 1.80 & 6.13 & 0.633 \\
\hline Q15 & -2.39 & 1.31 & 8.79 & 0.360 \\
\hline
\end{tabular}

Based on EFA, most of the items had acceptable factor loadings $\geq 0.3$ and communalities $\geq 0.09$. However, Q11 "I reuse disposable items to save cost" and Q12: "I clean blood-stained surfaces using chlorhexidine $0.5 \%$ in aqueous" were deleted due to their poor quality based on factor loading and communalities. Item Q7 "I use chlorhexidine $0.5 \%$ in aqueous for blood culture procedure" was kept as communalities value was only slightly below cut-off point.

After repeating the analysis, all remaining 10 items were determined acceptable (Table 5). Cronbach's alpha coefficients was 0.803 (95\% Cl: $0.733,0.803)$, indicating good internal consistency. The validated version of the questionnaire had a total of 23 items; knowledge (13 items) and practices ( 10 items) with 3 negative statements (Appendix 1).

\begin{tabular}{lll}
$\begin{array}{l}\text { Table 5. Results for exploratory factor analysis on practices } \\
\text { section }\end{array}$ & $\begin{array}{l}\text { Factor } \\
\text { loadings }\end{array}$ & Communalities \\
\hline Items & & \\
\hline Before modification & 0.5 & 0.28 \\
\hline Q3 & 0.3 & 0.10 \\
\hline Q4 & 0.6 & 0.39 \\
\hline Q5 & 0.4 & 0.13 \\
\hline Q6 & 0.3 & 0.07 \\
\hline Q7 & 0.5 & 0.24 \\
\hline Q8 & 0.8 & 0.59 \\
\hline Q9 & $\mathbf{0 . 2}$ & $\mathbf{0 . 0 3}$ \\
\hline Q11 & $\mathbf{0 . 2}$ & $\mathbf{0 . 0 3}$ \\
\hline Q12 & 0.8 & 0.61 \\
\hline Q13 & 0.7 & 0.46 \\
\hline Q14 & 0.7 & 0.46 \\
\hline Q15 & & \\
\hline After modification & 0.5 & 0.27 \\
\hline Q3 & 0.3 & 0.09 \\
\hline Q4 & 0.6 & 0.39 \\
\hline Q5 & 0.3 & 0.12 \\
\hline Q6 & 0.3 & $\mathbf{0 . 0 7}$ \\
\hline Q7 & 0.5 & 0.23 \\
\hline Q8 & 0.8 & 0.60 \\
\hline Q9 & 0.8 & 0.65 \\
\hline Q13 & 0.7 & 0.48 \\
\hline Q14 & 0.7 & 0.43 \\
\hline Q15 & & \\
\hline & & \\
\hline
\end{tabular}

\section{Discussion}

Malaysia is a diverse country with Bahasa Melayu as the mother tongue (28). It is for this reason that this study aimed to develop and validate a questionnaire on knowledge and practices of disinfection and sterilization among healthcare workers in Bahasa Melayu. Our findings indicated that the questionnaire managed to achieve an acceptable level of response process and good internal structure. This was achieved partly because of the rigorous development and validation process that was based on standard recommendations or guidelines as well as scientific articles $(29,30)$.

The first step of questionnaire development is the articulation of domains and item generation (29). Once the domain is delineated, the item pool can then be identified (29). An initial 30 items were prepared, including knowledge (15 items) and practices (15 items). With regard to the type of responses to these questions, items for knowledge had a polytomous answer option. A middle response of "Uncertain" was chosen to elicit the correct response. By treating it the same way as an incorrect answer would, the response was turned into dichotomous 
(31). As for the practices section, a Likert-type response scale presented in an ordinal manner is used to reflect the entire measurement continuum (29).

$\mathrm{CVI}$ is a common reported measure of content validity and has been around for many years (32). It works by asking panel of experts to rate each scale item concerning its relevance to the underlying construct with a 4-point ordinal scale. It is recommended a minimum of 3 experts, but not more than 10 . As the questionnaire was validated by 9 experts, a CVI cut-off point was set at $0.78(16)$. The results showed that I-CVI values of the present questionnaire were acceptable, indicating that the items were relevant with the sections.

To establish the response process validity, FVI was used to assess the clarity of the items. FVI values were calculated from 12 target population who completed the questionnaire. This decision was according to Yusoff (20) who noted that the number of experts for content validation should not be less than 10 raters (17). Based on his other work, it was resolved that all items had FVI $>0.70$ since they were considered as fairly understood by participants and were able to remain in the final validated questionnaire through confirmatory analysis (18).

From 2PL-IRT results, the knowledge section showed good psychometric properties in the validation study. With regard to the difficulty parameter, all items were within the respectable range. For the discrimination parameter, all values were acceptable except for Q10. All items but one which was Q13 fitted the 2PLIRT model with $p$ values of $>0.05$. However, both were retained, given their importance in the assessment of knowledge about disinfection and sterilization.

For EFA, factor loadings $\geq 0.3$ or 0.4 are usually considered in the interpretation (25). Communalities were calculated as sum of square of factor loading (33), which means that if factor loading of 0.3 is chosen, the threshold for communalities should be set at 0.09 . Based on those values, we had to omit 2 items which were Q11 and Q12 in the practices section but decided to maintain Q7 as the communality value was only inconsiderably below 0.09 .

The reliability of the questionnaire was also tested to measure the stability of the questionnaire and the consistency of the response. For this purpose, Cronbach's alpha coefficient is commonly used to reflect the internal consistency. Even though the respectable value may vary according to different literature, an instrument is often considered as reliable when the Cronbach's alpha coefficient reaches the value of 0.70 as depicted in our study (27).

The present study has several important limitations. The respondents were recruited only from a single tertiary hospital in Kelantan with moderate sample size which might not represent the whole population of healthcare workers in Malaysia. In addition to that, the use of convenience sampling could lead to sampling bias and hence, compromised the results obtained. As the questionnaire was developed in Bahasa Melayu, it was not possible to predict how well it would perform in other languages.

\section{Conclusion}

A self-administered questionnaire on knowledge and practices of disinfection and sterilization among healthcare workers was developed and validated. It consisted of 2 sections with 23 items, including knowledge (13 items) and practices (10 items). The questionnaire was proven to be psychometrically valid based on the results of 2PL-IRT and EFA. Future recommendation is for confirmatory analysis to be carried out to verify and maximize the psychometric credentials of the questionnaire.

\section{Acknowledgement}

The authors would like to thank the Director General of Health Malaysia for his permission to publish this article. No external organization was involved in this study as it was selffunded by the authors.

\section{Ethics}

Ethics Committee Approval: This research was registered with the National Medical Research Registry (NMRR-18-262441500) while ethical approval was obtained from the Medical Research and Ethics Committee (MREC), Ministry of Health Malaysia on 19 May 2018.

Informed Consent: Consent form was filled out by all participants.

Peer-review: Externally peer-reviewed.

\section{Authorship Contributions}

Surgical and Medical Practices: N.M.A.B., N.I.A.Z., Concept: N.L.A., S.H.S., N.I.A.Z., N.S.F.M., Design: N.L.A., S.H.S., N.I.A.Z., N.S.F.M., Data Collection or Processing: N.L.A., N.M.A.B., N.I.A.R., N.M.M., A.S.M.H.M., N.A.M., Analysis or Interpretation: N.L.A., Literature Search: N.L.A., N.M.A.B., N.I.A.R., N.M.M., A.S.M.H.M., N.A.M., Writing: N.L.A.

Conflict of Interest: No conflict of interest was declared by the authors.

Financial Disclosure: The authors declared that this study received no financial support.

\section{References}

1. Dellinger EP. Prevention of Hospital-Acquired Infections. Surg Infect (Larchmt). 2016;17:422-426.

2. Khan HA, Baig FK, Mehboob R. Nosocomial infections: Epidemiology, prevention, control and surveillance. Asian Pac J Trop Biomed. 2017;7:478-482. 
3. Haque M, Sartelli M, McKimm J, Abu Bakar M. Health careassociated infections - an overview. Infect Drug Resist. 2018;11:2321-2333.

4. World Health Organization. The burden of health care-associated infection. 2009. Last Accessed Date: 01.11.2021.

5. Hughes AJ, Ariffin N, Huat TL, et al. Prevalence of nosocomial infection and antibiotic use at a university medical center in Malaysia. Infect Control Hosp Epidemiol. 2005;26:100-104

6. Inweregbu K, Dave J, Pittard A. Nosocomial infections. Continuing Education in Anaesthesia, Critical Care \& Pain. 2005;5:14-17.

7. Dancer SJ. The role of environmental cleaning in the control of hospital-acquired infection. J Hosp Infect. 2009;73:378385.

8. Ministry of Health Malaysia. Policies and procedures of infection prevention and control. 2012. Last Accessed Date: 01.11.2021. Available from: https://www.moh.gov.my/

9. Rutala WA, Weber DJ, Healthcare Infection Control Practices Advisory Committee (HISPAC). Guideline for disinfection and sterilization in healthcare facilities. 2008. Last Accessed Date: 01.11.2021. Available from: https:// www.cdc.gov/infectioncontrol/pdf/guidelines/disinfectionguidelines-H.pdf

10. Siddiqui HK, Ikram K, Aftab NH, Uzair F. Knowledge and practice of sterilization among different healthcare workers. Pakistan Oral \& Dental Journal. 2014;34:507-509.

11. Sinha DK, Kumar C, Gupta A, Nayak L, Subhash S, Kumari R. Knowledge and practices about sterilization and disinfection. J Family Med Prim Care. 2020;9:793-797.

12. Sessa A, Di Giuseppe G, Albano L, Angelillo IF; Collaborative Working Group. An investigation of nurses knowledge, attitudes, and practices regarding disinfection procedures in Italy. BMC Infect Dis. 2011;11:148.

13. Sachdeva A, Sharma A, Bhateja S, Arora G. Knowledge, attitudes, and practices regarding sterilization protocol among undergraduate dental students in Faridabad City: A questionnaire-based study. 2019;31:4-10.

14. Keah KC, Jegathesan M, Tan SC, et al. An evaluation of knowledge and awareness of disinfection and sterilization among health care workers. Southeast Asian J Trop Med Public Health. 1995;26:51-56.

15. Arifin WN. A web-based sample size calculator for reliability studies. Educ Med J. 2018;10:67-76.

16. Microsoft Corporation. Microsoft Excel. 2018. Last Accessed Date: 01.11.2021. Available from: https://www. microsoft.com

17. R Core Team. R: A language and environment for statistical computing. R Foundation for Statistical Computing. Vienna; Austria; 2016. Last Accessed Date: 01.11.2021. Available from: https://www.eea.europa.eu/data-and- maps/indicators/oxygen-consuming-substances-in-rivers/ r-development-core-team-2006

18. R Studio Team. RStudio: Integrated development for $\mathrm{R}$. RStudio, PBC, Boston, MA. 2020. Last Accessed Date: 01.11.2021. Available from: https://support.rstudio.com/hc/ en-us/articles/206212048-Citing-RStudio

19. Lynn MR. Determination and quantification of content validity. Nurs Res. 1986;35:382-385.

20. Yusoff MSB. ABC of response process validation and face validity index calculation. Educ Med J. 2019;11:55-61.

21. Mahadi NF, Chin RWA, Chua YY, et al. Malay Language translation and validation of the Oldenburg Burnout Inventory Measuring Burnout. Educ Med J. 2018;10:27-40.

22. Rizopoulos D. Itm: An R package for latent variable modeling and item response theory analyses. J Stat Softw. 2006;17:1-25.

23. Arifin WN, Yusoff MSB. Item response theory for medical educationists. Educ Med J. 2017;9:69-81.

24. Revelle W. Psych: Procedures for personality and psychological research. Northwestern University, Evanston, Illinois, USA. 2016.

25. Izquierdo I, Olea J, Abad FJ. Exploratory factor analysis in validation studies: uses and recommendations. Psicothema. 2014;26:395-400.

26. Ford JK, MacCallum RC, Tait M. The application of exploratory factor analysis in applied psychology: A critical review and analysis. Pers Psychol. 1986;39:291-314.

27. Taber KS. The use of Cronbach's alpha when developing and reporting research instruments in science education. Res Sci Educ. 2018;48:1273-1296.

28. Montesino MU. Multi-ethnicity in the Malaysian workplace: The net balance of 35 years of affirmative policies as observed by a foreign visitor. Online Submiss. 2007;1-8.

29. Boateng GO, Neilands TB, Frongillo EA, Melgar-Quiñonez HR, Young SL. Best Practices for Developing and Validating Scales for Health, Social, and Behavioral Research: A Primer. Front Public Health. 2018;6:149.

30. McCoach DB, Gable RK, Madura JP. Instrument development in the affective domain: School and corporate applications. 3rd ed. New York, Springer Publishing; 2013.

31. Groothuis PA, Whitehead JC. Does don't know mean no? Analysis of "don't know" responses in dichotomous choice contingent valuation questions. Appl Econ. 2002;34:19351940.

32. Polit DF, Beck CT. The content validity index: are you sure you know what's being reported? Critique and recommendations. Res Nurs Health. 2006;29:489-497.

33. Yong AG, Pearce S. A beginner's guide to factor analysis : Focusing on exploratory factor analysis. Tutor Quant Methods Psychol. 2013;9:79-94.

Click for Appendix 1 access link: http://glns.co/m07dd 